\section{From the CDC}

\section{Reduced chance of HIV-infection from donor blood}

The probability of being infected with the human immunodeficiency virus (HIV) via blood transfusion appears to be lower than previously thought.

Number crunchers at the Centers for Disease Control and Prevention and the National American Red Cross estimate that one of every 450,000 to 660,000 blood donations may be infected with the HIV. Previous estimates held that one of every 153,000 to 225,000 blood donations carried the risk of such infection.

Because the average number of donors needed for each blood transfusion is 5.4 , the chances of a single transfusion recipient being infected is one in 83,000 to one in 122,000 , according to officials.

These numbers are based on donations made at American Red Cross centers nationwide between 1992 and 1993. Of the 12 million blood donations made in the United States each year, $50 \%$ come from the American Red Cross.

A shorter time for the development of antibodies to the HIV and, therefore, earlier detection of these antibodies is a primary reason for the decrease in contamination.

\section{From the FTC}

\section{Proposal to require cigarette makers to show range of tar, nicotine levels}

Those single lo.tar and nicotine numbers prominently featured in cigarette advertisements will soon be passé if a new proposal from the Federal Trade Commission goes into effect. The proposal would require that cigarette makers include a range of tar and nicotine levels in their advertisements. Currently, the lowest level of tar and nicotine are displayed.

The commission also plans on warning cigarette smokers that the actual amount of tar and nicotine they inhale depends on their personal smoking habits.

Tar and nicotine levels are measured using a machine that mimicsbut doesn't duplicate exactly-human smokers. Plans are in the works to make the "smoking" machine closer to that of human cigarette smokers by adjusting the way the machine inhales.

The proposal would only affect brand-name cigarettes.

\section{American Osteopathic Association}

CME Video: "Back to the Future: Primary Care in America," 27

\section{Bayer Corporation \\ Adalat CC, $37-40$}

\section{Bock Pharmacal Company Dynabac, 5, 6}

\section{Deborah Heart and Lung Center, 24, 61}

\section{Forest Laboratories}

Esgic Plus, 9, 10

Lorcet 10/650, 15, 16

\section{Grandview Hospital \& \\ Medical Center, 61}

Janssen Pharmaceutica Sporanox, 17-21

\author{
Wyeth-Ayerst Laboratories
}

Lodine, Cover 2, 1, 2

\section{Zeneca Pharmaceuticals}

Sular, 11

Zestril, Cover 3, Cover 4 